\title{
A Group Decision Making Approach Considering Self-Confidence Behaviors and Its Application in Environmental Pollution Emergency Management
}

\author{
Xia Liu ${ }^{1,2}$, Yejun Xu ${ }^{1}\left(\right.$, Yao Ge ${ }^{3, *}$, Weike Zhang ${ }^{2,3}$ and Francisco Herrera ${ }^{2,4}(\mathbb{D}$ \\ 1 Business School, Hohai University, Nanjing 211100, China; liuxia@hhu.edu.cn (X.L.); xuyejohn@163.com (Y.X.) \\ 2 Andalusian Research Institute in Data Science and Computational Intelligence (DaSCI), \\ University of Granada, 18071 Granada, Spain; zhangwk@correo.ugr.es (W.Z.); herrera@decsai.ugr.es (F.H.) \\ 3 School of Economics, Sichuan University, Chengdu 610064, China \\ 4 Faculty of Computing and Information Technology, King Abdulaziz University, Jeddah 21589, Saudi Arabia \\ * Correspondence: sidlelz@126.com; Tel.: +86-189-094-26666
}

Received: 1 December 2018; Accepted: 25 January 2019; Published: 29 January 2019

\begin{abstract}
Self-confidence as one of the human psychological behaviors has important influence on emergency management decision making, which has been ignored in existing methods. To fill this gap, we dedicate to design a group decision making approach considering self-confidence behaviors and apply it to the environmental pollution emergency management. In the proposed method, the self-confident fuzzy preference relations are utilized to express experts' evaluations. This new type of preference relations allow experts to express multiple self-confidence levels when providing their evaluations, which can deal with the self-confidence of them well. To apply the proposed group decision making method to environmental pollution emergency management, a novel determination of the decision weights of experts is given combining the subjective and objective weights. The subjective weight can be directly assigned by organizer, while the objective weight is determined by the self-confidence degree of experts on their evaluations. Afterwards, by utilizing the weighted averaging operator, the individuals' evaluations can be aggregated into a collective one. To do that, some operational laws for self-confident fuzzy preference relations are introduced. And then, a self-confidence score function is designed to get the best solution for environmental pollution emergency management. Finally, some analyses and discussions show that the proposed method is feasible and effective.
\end{abstract}

Keywords: group decision making; self-confidence; decision weight; environmental pollution emergency management; score function

\section{Introduction}

Group decision making (GDM) refers to a condition whereby a group of experts (decision makers) are involved in a decision process, provide their evaluations regarding the provided alternatives, and select an optimal decision by the aggregation of their opinions [1]. Generally, in GDM problems, preference relations are the most common representation of information, because it is a useful tool in modeling decision processes. The main advantage of preference relations is that individuals can focus exclusively on two alternatives at a time, which facilitating the expression of their opinions [2,3], and then making them more accurate than non-pairwise methods [4]. To date, many different types of preference relations have been proposed and widely used in decision making problems [5-11].

As we all know, real GDM situations involve not only the fields of mathematics but also the human psychological behaviors [12]. Self-confidence as one of the human psychological behaviors has important influence on decision making [13-17]. Hence, it would be of great importance to design 
a GDM approach considering self-confidence behavior. To do so, Liu, et al. [18] introduced a new type of preference relation called self-confident fuzzy preference relation (SC-FPR), which allows experts to express multiple self-confidence levels when providing their evaluations. In an SC-FPR, the elements are composed of two components, the former represents the preference degree between pairs of alternatives, and the latter denotes the self-confidence level associated to the first component. Obviously, the second element indicates a psychological expression for personal self-estimation.

Nowadays, due to a lack of attention to the negative effects of highly developed industries, environmental pollution problems, which are one of the three major crises in the world, are emerging one after another. Specially, in China, with the rapid development of economic and technology, the environmental pollution turns into a high-risk period, a series of environmental pollution events have occurred in recent years. For instance, the dead fish incident in Baiyangdian in Hebei Province in 2006 [19], the water pollution in Taihu Lake in 2007 [20], the cadmium pollution in Longjiang River in Guangxi Province in 2012 [21], the major water pollution incident in the Songhua River in 2015 [22], the pig deaths in Songiiang River in Shanghai in 2017 [23] and so on. In order to improve the efficiency of environmental pollution emergency management, as well as to reduce the risk and damage of environmental pollution, the Chinese government is also increasingly investing in environmental protection. Figure 1 shows the per year investment in environmental pollution emergency management in China from 2012 to 2016.

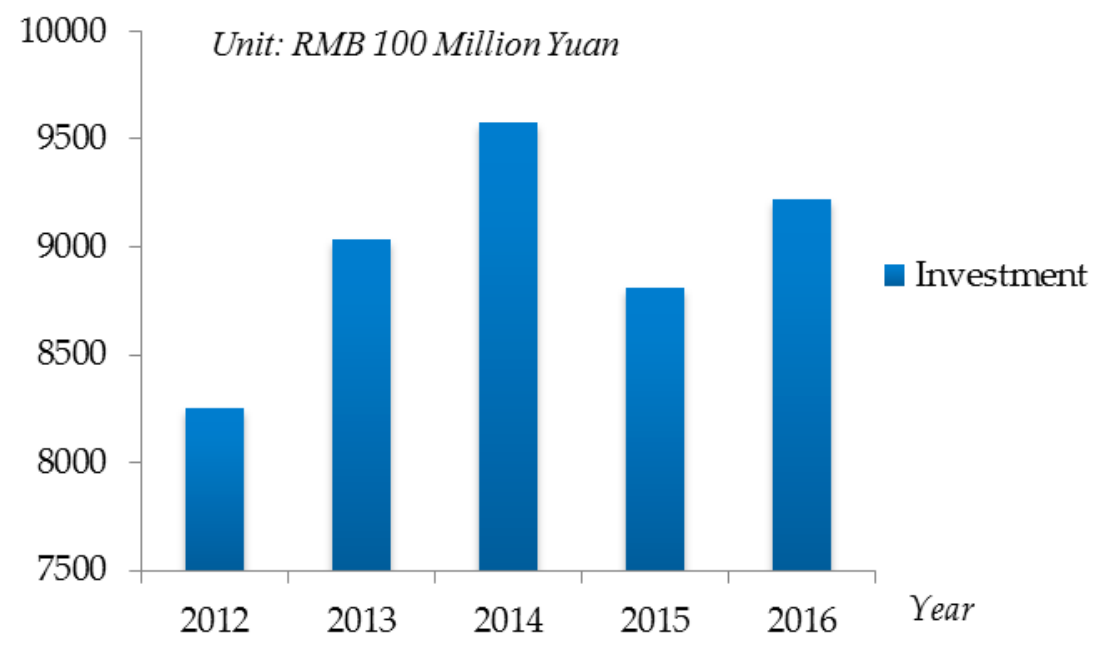

Figure 1. The per year investment in environmental pollution emergency management from 2012 to 2016, China.

Although the Chinese government and the public are now paying great attention to environmental protection, the environmental pollution problem has not fundamentally been resolved yet. Table 1 shows the number of the environmental emergencies occurred per year from 2012 to 2016 in China. Clearly, from Table 1, we can observe that serious environmental emergencies are still common in China. In other words, the environmental pollution emergency management is still a hotspot that cannot be ignored in China.

Table 1. The number of the environmental emergencies occurred per year from 2012 to 2016, China.

\begin{tabular}{|c|c|c|c|c|c|}
\hline Times Year & 2012 & 2013 & 2014 & 2015 & 2016 \\
\hline Total Number & 542 & 712 & 471 & 334 & 304 \\
\hline Severe & 5 & 3 & 3 & 3 & 3 \\
\hline Large & 5 & 12 & 16 & 5 & 5 \\
\hline General & 532 & 697 & 452 & 326 & 296 \\
\hline
\end{tabular}


Up to now, there are several studies related to environmental pollution emergency management. Such as, Yang [24] proposed an environmental emergency response plan for EHS management of mega-construction projects. Shao, et al. [25] presented an integrated environmental risk assessment, as well as designed a whole process management system in chemical industry parks. Zhang and Wang [26] suggested that strengthening the quality management is the most important role of sudden environmental pollution emergency monitoring. In addition, from the perspective of the sustainability and resilience, Marchese, et al. [27] reviewed the integrated use of sustainability and resilience in an environmental management context. Cao, et al. [28] conducted an analytical study of environmental incidents from 2006 to 2015 in China, which has useful implications for policy-making and environmental management. Based on the principle of implementing green policy and community participation, Ayeni [29] discussed the environmental policies for emergency management and public safety. Rämö, et al. [30] made an environmental risk assessment of pesticides in the River Madre de Dios, Costa Rica using PERPEST (predict the ecological risks of pesticides), SSD (species sensitivity distributions), and msPAF (multi-substance potentially affected fraction) models and so on. Through the review of the above literature, it reveals that environmental pollution problem is still a hotpot of the sustainable development of human beings. Meanwhile, all these existing methods have made an important progress in improving the efficiency of environmental pollution emergency management.

As far as we know, one of the most crucial problems concerning the environmental pollution emergency management is to choose a reasonable alternative to reduce the risk and probability of pollution. Thus, in some cases, the environmental pollution emergency management actually can be seen as a GDM problem. However, according to the above literature reviewed regarding the environmental pollution emergency management, we find that from the perspective of GDM, and take the self-confidence behaviors of experts into account, to discuss the environmental pollution emergency management is still a challenge.

To fill the gap mentioned above, we devote this paper to discussing a GDM approach considering self-confidence behaviors and apply it to environmental pollution emergency management. In the proposed method, the SC-FPRs are utilized to express experts' evaluations. Subsequently, a novel determination of the decision weights of experts is given to apply the proposed GDM method to environmental pollution emergency management. Furthermore, by utilizing the weighted averaging (WA) operator, the individuals' evaluations can be aggregated into a collective one. To do that, some new operational laws for SC-FPR are introduced. And then, a self-confidence score function (SCS) is designed to get the best solution for environmental pollution emergency management. The main novelties and contributions of this paper are listed as follows:

1. Experts' self-confidence levels are taken into account in GDM problems. That is, experts are allowed use SC-FPRs to express their evaluations, which can deal with their self-confidence psychological behaviors well. Meanwhile, some new operation laws for SC-FPRs are proposed to apply to environmental pollution emergency management.

2. A novel determination of the decision weights of experts is given combining the subjective and objective weights. On one hand, the subjective weight can be directly assigned by organizer. On the other hand, the objective weight is determined by the self-confidence degree (SCD) of experts on their evaluations.

3. An SCD is presented to measure the overall self-confidence levels of experts on their evaluations, as well as to be utilized to assign their objective weights in environmental pollution emergency management.

4. An SCS function for SC-FPRs is designed to select the best alternative(s) in environmental pollution emergency management. We rank alternatives by computing the SCSs of the collective evaluations. And then, the best alternative is the one with the highest SCS.

The effectiveness of the research in this paper is demonstrated by a case of study of environmental pollution emergency management. Moreover, some comparative analyses and discussions are provided 
to validity the self-confidence of experts' impact on final decision. From the results, it concludes that the self-confidence levels of experts have important influence on the alternative ranking in environmental pollution emergency management.

The rest of this paper is organized as follows: in Section 2, we review some preliminaries regarding the 2-tuple linguistic ordinal scale model and SC-FPRs. In Section 3, a determination of the decision weights of experts and the GDM approach considering self-confidence are presented. Section 4 applies the proposed GDM method to resolve an environmental pollution emergency management. Subsequently, some analyses and discussions are shown in Section 5. Finally, the conclusions are summarized in Section 6.

\section{Preliminaries}

This section reviews some related knowledge regarding the 2-tuple linguistic ordinal scale model, and SC-FPRs. For simplicity, some symbol descriptions which used in the whole paper are shown in Appendix A.

\subsection{2-Tuple Linguistic Ordinal Scale Model}

To carry out ordinal computing with words when dealing with the linguistic self-confidence in GDM problems, the 2-tuple linguistic ordinal scale model is reviewed as follows.

Let $S=\left\{s_{i} \mid i=0,1, \ldots, g\right\}$ be a linguistic term set. The term $s_{i}$ denotes a possible value of a linguistic variable, and the order on set $S$ is assumed that $s_{i}>s_{j}$ if and only if $i>j$. Then, the concept of 2-tuple fuzzy linguistic model is given below:

Definition 1 [31]. Let $\beta \in[0, g]$ be a number in the granularity interval of the linguistic term set $S$. Let $i=\operatorname{round}(\beta)$ and $\alpha=\beta-i$ be two values such that $i \in[0, g]$, and $\alpha \in[-0.5,0.5)$. Then $\alpha$ is called a symbolic translation, and the round is the usual round operation.

Herrera and Martínez [31] developed a linguistic representation model which represents the linguistic information by means of 2-tuples $\left(s_{i}, \alpha\right), s_{i} \in S$ and $\alpha \in[-0.5,0.5)$. Obviously, the 2-tuple linguistic model defines a function to make transformation between linguistic 2-tuples and numerical values.

Definition 2 [31]. Let $S$ be a linguistic term set with the granularity interval $[0, g]$. The 2-tuple that expresses the equivalent information to $\beta \in[0, g]$ is obtained with the following function: $\Delta:[0, g] \rightarrow S \times[-0.5,0.5)$, where:

$$
\Delta(\beta)=\left(s_{i}, \alpha\right), \text { with }\left\{\begin{array}{ll}
s_{i}, & i=\operatorname{round}(\beta) \\
\alpha=\beta-i, & \alpha \in[-0.5,0.5)
\end{array} .\right.
$$

Moreover, the $\Delta$ represents one to one mapping function. For a linguistic term set $S$, and a 2-tuple $\left(s_{i}, \alpha\right)$, there is always an inverse function $\Delta^{-}$can from a 2-tuple returns its equivalent numerical value $\beta \in[0, g]:$

$$
\begin{gathered}
\Delta^{-}: S \times[-0.5,0.5) \rightarrow[0, g] \\
\Delta^{-}\left(s_{i}, \alpha\right)=i+\alpha=\beta .
\end{gathered}
$$

Clearly, the conversion of a linguistic term into a linguistic 2-tuple consist of adding a value zero as symbolic translation $s_{i} \in S \Rightarrow\left(s_{i}, 0\right)$, i.e., $\Delta^{-}\left(s_{i}, 0\right)=\Delta^{-}\left(s_{i}\right)$. Additionally, some computations and operators were presented to deal with 2-tuple linguistic information in [31-33] as follows:

(1) 2-tuples comparison operator: Let $\left(s_{v}, \alpha\right)$ and $\left(s_{l}, \gamma\right)$ be two 2-tuples, then:

- $\quad$ if $v<l$, then $\left(s_{v}, \alpha\right)$ is smaller than $\left(s_{l}, \gamma\right)$; 
- $\quad$ if $v=l$, then

(a) if $\alpha=\gamma$, then $\left(s_{v}, \alpha\right),\left(s_{l}, \gamma\right)$ represents the same information;

(b) if $\alpha<\gamma$, then $\left(s_{v}, \alpha\right)$ is smaller than $\left(s_{l}, \gamma\right)$;

(2) A 2-tuple negation operator:

$$
\operatorname{Neg}\left(s_{i}, \alpha\right)=\Delta\left(g-\Delta^{-}\left(s_{i}, \alpha\right)\right)
$$

\subsection{Self-Confident Fuzzy Preference Relations}

As we all know, real GDM problems involve not only the fields of mathematics but also human psychological behavior. Self-confidence as one of the human psychological traits that has an important influence on decision making [13-17]. Hence, it would be of great importance to take the self-confidence behaviors of experts into account in GDM problems. To do so, a new preference relation called SC-FPR introduced by [18], which can be utilized to deal with the self-confidence of expert well.

Suppose a linguistic term $S^{S L}=\left\{s_{i} \mid i=0,1, \ldots, g\right\}$ is used to characterize experts' self-confidence over their evaluations. Without loss of generality, this paper assumes that experts use a nine linguistic-term set $S^{S L}=\left\{s_{0}, s_{1}, \ldots, s_{8}\right\}$ to express their self-confidence levels. The detailed information of is shown in Table 2.

Table 2. Nine self-confidence language terms with its semantics.

\begin{tabular}{cc}
\hline Self-Confidence Language & Semantics \\
\hline$s_{0}$ & None \\
$s_{1}$ & Very low \\
$s_{2}$ & Low \\
$s_{3}$ & Slightly low \\
$s_{4}$ & Medium \\
$s_{5}$ & Slightly high \\
$s_{6}$ & High \\
$s_{7}$ & Very high \\
$s_{8}$ & Prefect \\
\hline
\end{tabular}

The definition of SC-FPR introduced by [18] is given below:

Definition 3 [18]. A matrix $P=\left(p_{i j}, l_{i j}\right)_{n \times n}$ is called an SC-FPR, where the first component $p_{i j} \in[0,1]$ represents the preference degree of the alternative $x_{i}$ over $x_{j}$. The second one $l_{i j} \in S^{S L}$ denotes the self-confidence level associated to the first element $p_{i j}$. The following conditions are assumed: $p_{i j}+p_{j i}=1, p_{i i}=0.5, l_{i j}=l_{j i}$ and $l_{i i}=s_{g}$ for $\forall i, j=1,2, \ldots, n$.

Note: As far as we know, the Z-number which introduced by Zadeh [34] is consists of an ordered pair of fuzzy numbers. The first element denotes the constraint on the values on the real-valued uncertain variable, and the second represents the measure of reliability of the first element. Therefore, in some cases, the elements in an SC-FPR also can be seen as a Z-number.

Example 1. Assume that an expert assesses four alternatives and provides an SC-FPR as follows:

$$
P=\left(\begin{array}{llll}
\left(0.5, s_{8}\right) & \left(0.4, s_{5}\right) & \left(0.2, s_{7}\right) & \left(0.7, s_{8}\right) \\
\left(0.6, s_{5}\right) & \left(0.5, s_{8}\right) & \left(0.8, s_{6}\right) & \left(0.9, s_{4}\right) \\
\left(0.8, s_{7}\right) & \left(0.2, s_{6}\right) & \left(0.5, s_{8}\right) & \left(0.6, s_{5}\right) \\
\left(0.3, s_{8}\right) & \left(0.1, s_{4}\right) & \left(0.4, s_{5}\right) & \left(0.5, s_{8}\right)
\end{array}\right)
$$

In the $P, p_{12}=0.4$ means the preference degree of the alternative $x_{1}$ over the alternative $x_{2}$ is 0.4 , and the $l_{12}=s_{5}$ shows the expert's self-confidence level associated to $p_{12}$ is $s_{5}$. That is, the expert 
is slightly high self-confident in her/his evaluation. In addition, all the other elements in $P$ can be explained similarly.

In order to effectively aggregate the information in GDM problems, and apply the SC-FPRs to environmental pollution emergency management, based on the transitivity rule, some new operational laws of 2-tuples in SC-FPR are defined by [35] as follows.

Definition 4 [35]. Assume $\left(p_{i}, l_{i}\right),\left(p_{z}, l_{z}\right)$ are two 2-tuples, $p_{i}, p_{z}$ are the fuzzy preference values, and $l_{i}, l_{z}$ are corresponding self-confidence levels, where $l_{i}, l_{z} \in S^{S L}, \lambda \in[0,1]$. Then, we have the following operations:

(1) $\left(p_{i}, l_{i}\right)+\left(p_{z}, l_{z}\right)=\left(p_{i}+p_{z}, \min \left\{l_{i}, l_{z}\right\}\right)$;

(2) $\left(p_{i}, l_{i}\right)-\left(p_{z}, l_{z}\right)=\left(p_{i}-p_{z}, \min \left\{l_{i}, l_{z}\right\}\right)$;

(3) $\left(p_{z}, l_{z}\right)-\lambda=\left(p_{z}-\lambda, l_{z}\right)$;

(4) $\left(p_{z}, l_{z}\right)^{\lambda}=\left(\left(p_{z}\right)^{\lambda}, l_{z}\right)$;

(5) $\lambda\left(p_{z}, l_{z}\right)=\left(\lambda p_{z}, l_{z}\right)$.

\section{A GDM Approach Considering Self-Confidence Behaviors}

In this section, a GDM approach considering self-confidence behaviors is proposed. Firstly, in Section 3.1, a novel determination of the decision weights of experts considering self-confidence level is presented. Afterwards, the detailed decision processes for GDM considering self-confidence are presented in Section 3.2.

\subsection{Determine the Decision Weight of Expert Considering Self-Confidence}

One of the necessary stages in GDM analysis is to combine the individuals' evaluations and weights to form a collective evaluation. Thus, the determination of the decision weight of expert is of great importance.

Generally, in the most existing methods, all experts involved in decision making are directly assigned equal weights by the organizer. That is, each expert is assumed to play an equally important role in GDM. Nevertheless, due to experts have different knowledge or experience, they may express different self-confidence levels when providing their evaluations. The self-confidence usually indicates the self-recognition of expert on her/his evaluation, the higher the self-confidence will imply the more the knowledge or experience of expert for GDM problems. Hence, the self-confidence levels of experts should be considered on the determination of the decision weight of expert. To do so, a novel determination of the decision weights of experts considering self-confidence levels is presented in this research. It mainly contains the following three stages:

Stage 1. The organizer directly assigns the subjective weight for each expert denoted as $w^{\text {sub }}=$ $\left(w_{1}^{\text {sub }}, w_{2}^{\text {sub }}, \ldots, w_{m}^{\text {sub }}\right)$, where $w_{k}^{\text {sub }}$ represents the subjective weight of expert $e_{k}$, such that $\sum_{k=1}^{m} w_{k}^{\text {sub }}=1$ and $w_{k}^{\text {sub }} \in[0,1], k=1,2, \ldots, m$. Considering the fairness among experts, the $w_{k}^{\text {sub }}$ can be determined by the number of participators in decision making as follows:

$$
w_{k}^{s u b}=\frac{1}{k}, k=1,2, \ldots m
$$

Stage 2. To determine the objective weights of experts based on the SCDs in their evaluations. The detailed approach is described below:

Actually, as per the SC-FPR $P=\left(p_{i j}, l_{i j}\right)_{n \times n}$ given by an expert, it can be seen as a combination of FPR $\widetilde{P}=\left(\widetilde{p}_{i j}\right)_{n \times n}$ and a self-confidence matrix $\widetilde{L}=\left(\widetilde{l}_{i j}\right)_{n \times n^{\prime}}$ where $\widetilde{p}_{i j}=p_{i j}$ and $\widetilde{l}_{i j}=l_{i j}$ for $\forall i, j=1,2, \ldots, n$. As aforementioned, the higher the self-confidence of the experts on their evaluations, the more the knowledge or experience of them for decision making problems will be. Based on this hypothesis, we propose to measure the $S C D$ of expert by measuring the deviation level between the 
self-confidence matrix of expert and the maximal self-confidence matrix. To do so, the self-confidence deviation level (SCDL) between the self-confidence matrix of SC-FPR given by expert and the maximal self-confidence matrix is defined by:

Definition 5. Let $P_{k}=\left(p_{i j, k}, l_{i j, k}\right)_{n \times n}$ be an SC-FPR given by an expert $e_{k}$, and $\widetilde{L}_{k}=\left(\widetilde{l}_{i j, k}\right)_{n \times n}$ be the corresponding self-confidence matrix of the expert $e_{k}$. Let $L=\left(s_{g}\right)_{n \times n}$ be the maximal self-confidence matrix, where $\widetilde{l}_{i j, k}, s_{g} \in S^{S L}$. Then, the SCDL of $e_{k}(k=\{1,2, \ldots m\})$ is defined as:

$$
\operatorname{SCDL}\left(e_{k}\right)=\frac{2}{n(n-1)} \sum_{i=1}^{n-1} \sum_{j=i+1}^{n} d\left(\widetilde{L}_{k}, L\right)=\frac{2}{n(n-1)} \sum_{i=1}^{n-1} \sum_{j=i+1}^{n} \frac{\left|\Delta^{-}\left(\widetilde{l}_{i j, k}\right)-\Delta^{-}\left(s_{g}\right)\right|}{g}
$$

Note: Obviously, the $\operatorname{SCDL}\left(e_{k}\right)$ has the following characteristics:

(1) $\operatorname{SCDL}\left(e_{k}\right) \in[0,1]$;

(2) if $\operatorname{SCDL}\left(e_{k}\right)=0$, it means that the expert $e_{k}$ is completely self-confident in all of her/his evaluations.

Afterwards, the $S C D$ of the expert $e_{k}$ is given below:

$$
\operatorname{SCD}\left(e_{k}\right)=1-\operatorname{SCDL}\left(e_{k}\right)
$$

Similarly, we have $\operatorname{SCD}\left(e_{k}\right) \in[0,1]$. The higher the value of the $\operatorname{SCD}\left(e_{k}\right)$, the more the self-confidence levels of the expert $e_{k}$ in her/his evaluations will be.

As mentioned above, the $S C D$ s can reflect the experts' knowledge, abilities or experiences. The higher the value of $S C D$ of expert, the more the reliable of her/his assessment information will be. Moreover, the higher the quality and efficiency of emergency management will be. Thus, the expert who has most self-confident should be assigned larger weight in GDM problems. Let $w^{o b j}=$ $\left(w_{1}^{o b j}, w_{2}^{o b j}, \ldots, w_{m}^{o b j}\right)$ be the objective weight vectors of experts, where $w_{k}^{o b j}$ represents the objective weight of the expert $e_{k}(k=1,2, \ldots, m)$, the $w_{k}^{o b j}$ can be computed by:

$$
w_{k}^{o b j}=\frac{S C D\left(e_{k}\right)}{\sum_{k=1}^{m} S C D\left(e_{k}\right)}
$$

where $\sum_{k=1}^{m} w_{k}^{o b j}=1$ and $w_{k}^{o b j} \in[0,1], k=1,2, \ldots, m$.

Stage 3. Based on the above analysis, let $w=\left(w_{1}, w_{2}, \ldots, w_{k}\right)$ be the weight vector of experts, the $w_{k}$ can be determined by combing the subjective weight $w_{k}^{\text {sub }}$ and the objective weight $w_{k}^{o b j}$ as follows:

$$
w_{k}=\mu w_{k}^{s u b}+\tau w_{k}^{o b j}, k=1,2, \ldots, m
$$

where $\mu$ and $\tau$ are parameters to control the weight between $w_{k}^{s u b}$ and $w_{k}^{o b j}$ of expert $e_{k}$ $\mu, \tau \in[0,1]$ and $\mu+\tau=1$.

Note: As per Equation (5), we have the following two conclusions:

(1) if $\mu=1$, i.e., $\tau=0$, it indicates that the weight of expert does not consider the objective weight. In other words, the self-confidence of expert is not taken into account.

(2) if $\mu=0$, i.e., $\tau=1$, it represents that the subjective weight of expert is not considered.

Without loss of generality, this paper assumes that the subjective weight and the objective weight are equally important on determination of the decision weight of expert. Thus, we have $\mu=\tau=0.5$. 


\subsection{Detailed Decision Processes for GDM Considering Self-Confidence}

After the decision weights of experts are obtained, a collective evaluation can be computed by the WA operator. Let $P_{c}=\left(p_{i j, c}, l_{i j, c}\right)_{n \times n}$ be the collective evaluation, where:

$$
\left(p_{i j, c}, l_{i j, c}\right)=\sum_{k=1}^{m} w_{k}\left(p_{i j, k}, l_{i j, k}\right)
$$

According to the Definition 4 and Equation (6), the collective preference information can be computed. Subsequently, the GDM turns to a selection process. That is, we need to transform the collective preference information of the alternatives into a collective ranking, and then to get the best alternative for the GDM problem. To do so, for a collective SC-FPR, we propose to choose the best alternative by computing the $S C S$ of each alternative. The alternative with the highest $S C S$ should be chosen as the optimal alternative. The SCS function of SC-FPR is defined as:

Definition 6. Let $X=\left\{x_{1}, \ldots, x_{n}\right\}$ be an alternative set, and $P_{c}=\left(p_{i j, c}, l_{i j, c}\right)_{n \times n}$ be the collective SC-FPR of $G D M$, then the SCS of each alternative can be computed as follows:

$$
\operatorname{SCS}\left(x_{i}\right)=\frac{1}{n} \sum_{j=1}^{n}\left(p_{i j, c} \times \Delta^{-}\left(l_{i j, c}\right)\right), i=1,2, \ldots, n
$$

Note: As per Definition 6, the higher the value of the $\operatorname{SCS}\left(x_{i}\right)$, the more expert self-confident of the alternative $x_{i}$ will be. That is, if we have $S C S\left(x_{i}\right)>S C S\left(x_{j}\right)$, then $x_{i} \succ x_{j}, x_{i}, x_{j} \in X$.

In addition, the detailed GDM approach considering self-confidence is depicted in Algorithm 1.

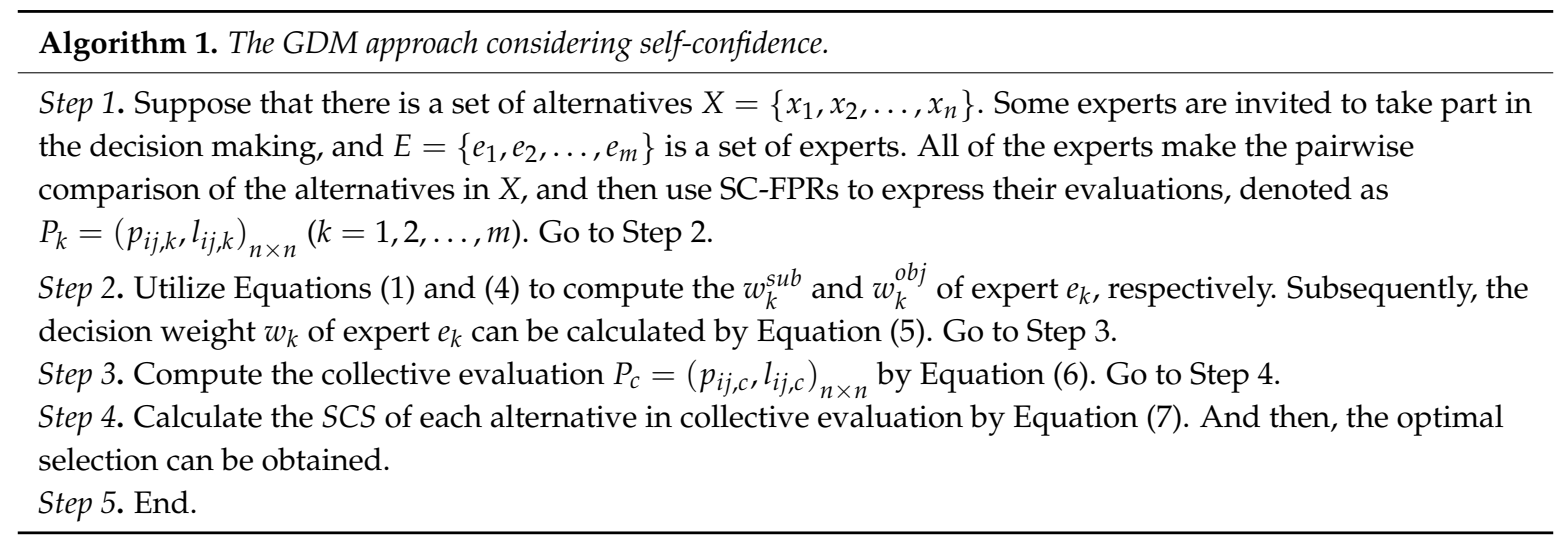

\section{Case Study: An Environmental Pollution Emergency Management}

Self-confidence as one of the human psychological behaviors has a great influence on emergency management decision making, which has been ignored in most existing studies. To fill this gap, in this section, we apply the proposed GDM method considering self-confidence to an environmental pollution emergency management. In Section 4.1, the environmental pollution emergency management description is given. An application of the proposed GDM method considering self-confidence to environmental pollution emergency management is shown in Section 4.2.

\subsection{Environmental Pollution Emergency Management Description}

With the rapid development of economic and technology, the environmental pollution in China turns into a high-risk period, a series of environmental pollution events have occurred recently. In order to improve the efficiency of the management of environmental pollution emergency, as well as to reduce the risk of environmental pollution, the city $Q$ decided to make an environmental pollution emergency plan. 
Combined with the policy of the national environmental protection department and the specific of the city $Q$, the organizer provides four environmental pollution emergency plans (possible solutions) $x_{1}, x_{2}, x_{3}, x_{4}$ to be chosen. Subsequently, four experts $e_{1}, e_{2}, e_{3}, e_{4}$ from the Environmental Protection Department, Emergency Management Department, and the Research Institute of Universities are invited to participate in the decision making. Considering the quality and efficiency of final decision, the organizer provides the following four important criteria for the experts:

- Resource allocation;

- The rescue time of environmental pollution emergency;

- The cost of investment;

- Other emergency safeguards.

Based on the above four criteria, each expert is invited to make a pairwise comparison for the provided alternatives, and then uses SC-FPR to express her/his evaluations. Meanwhile, the organizer assigns the equal subjective weight for each expert. In addition, as for the fuzzy preference values in the SC-FPR given by expert, we have the following explanations:

- if $p_{i j, k}=0.5$, it means that expert $e_{k}$ thinks there is indifference between alternatives $x_{i}$ and $x_{j}$, that is, $x_{i} \sim x_{j}$.

- if $0.5<p_{i j, k} \leq 1$, it means that expert $e_{k}$ thinks alternative $x_{i}$ is preferred to alternative $x_{j}$, that is, $x_{i} \succ x_{j}$. Specially, if $p_{i j, k}=1$, it indicates that expert $e_{k}$ thinks alternative $x_{i}$ is definitely preferred to alternative $x_{j}$.

- if $0 \leq p_{i j, k}<0.5$, it means that expert $e_{k}$ thinks alternative $x_{j}$ is preferred to alternative $x_{i}$, that is, $x_{j} \succ x_{i}$. Meanwhile, the smaller $p_{i j, k}$ the stronger the preference of $x_{j}$ over $x_{i}$.

\subsection{Application of the Proposed GDM Approach Considering Self-Confidence}

In this section, Algorithm 1 is utilized to select the best solution for the environmental pollution emergency management. The detailed steps are as follows:

Step 1. Suppose that the SC-FPRs given by these four experts are:

$$
\begin{aligned}
& P_{1}=\left(\begin{array}{llll}
\left(0.5, s_{8}\right) & \left(0.1, s_{5}\right) & \left(0.6, s_{7}\right) & \left(0.7, s_{4}\right) \\
\left(0.9, s_{5}\right) & \left(0.5, s_{8}\right) & \left(0.8, s_{6}\right) & \left(0.6, s_{4}\right) \\
\left(0.4, s_{7}\right) & \left(0.2, s_{6}\right) & \left(0.5, s_{8}\right) & \left(0.6, s_{5}\right) \\
\left(0.3, s_{4}\right) & \left(0.4, s_{4}\right) & \left(0.4, s_{5}\right) & \left(0.5, s_{8}\right) \\
\left(0.5, s_{8}\right) & \left(0.6, s_{3}\right) & \left(0.8, s_{5}\right) & \left(0.2, s_{3}\right) \\
\left(0.4, s_{3}\right) & \left(0.5, s_{8}\right) & \left(0.6, s_{4}\right) & \left(0.7, s_{6}\right) \\
\left(0.2, s_{5}\right) & \left(0.4, s_{4}\right) & \left(0.5, s_{8}\right) & \left(0.4, s_{3}\right) \\
\left(0.8, s_{3}\right) & \left(0.3, s_{6}\right) & \left(0.6, s_{3}\right) & \left(0.5, s_{8}\right)
\end{array}\right), \\
& P_{3}=\left(\begin{array}{llll}
\left(0.5, s_{8}\right) & \left(0.3, s_{6}\right) & \left(0.4, s_{5}\right) & \left(0.7, s_{4}\right) \\
\left(0.7, s_{6}\right) & \left(0.5, s_{8}\right) & \left(0.2, s_{6}\right) & \left(0.4, s_{3}\right) \\
\left(0.6, s_{5}\right) & \left(0.8, s_{6}\right) & \left(0.5, s_{8}\right) & \left(0.9, s_{2}\right) \\
\left(0.3, s_{4}\right) & \left(0.6, s_{3}\right) & \left(0.1, s_{2}\right) & \left(0.5, s_{8}\right)
\end{array}\right), \\
& P_{4}=\left(\begin{array}{llll}
\left(0.5, s_{8}\right) & \left(0.4, s_{5}\right) & \left(0.2, s_{6}\right) & \left(0.1, s_{5}\right) \\
\left(0.6, s_{5}\right) & \left(0.5, s_{8}\right) & \left(0.6, s_{6}\right) & \left(0.5, s_{1}\right) \\
\left(0.8, s_{6}\right) & \left(0.4, s_{6}\right) & \left(0.5, s_{8}\right) & \left(0.3, s_{7}\right) \\
\left(0.9, s_{5}\right) & \left(0.5, s_{1}\right) & \left(0.7, s_{7}\right) & \left(0.5, s_{8}\right)
\end{array}\right) .
\end{aligned}
$$

Step 2. By Equation (1), we get the subjective weights of experts $e_{k}(k=1,2,3,4)$ :

$$
w_{1}^{\text {sub }}=1 / 4, w_{2}^{\text {sub }}=1 / 4, w_{3}^{\text {sub }}=1 / 4, w_{4}^{\text {sub }}=1 / 4 .
$$


Afterwards, based on Definition 5, we have the self-confidence matrix $\widetilde{L}_{k}=\left(\widetilde{l}_{i j, k}\right)_{n \times n}$ of experts $e_{k}$ $(k=1,2,3,4)$ :

$$
\begin{aligned}
& \widetilde{L}_{1}=\left(\begin{array}{llll}
s_{8} & s_{5} & s_{7} & s_{4} \\
s_{5} & s_{8} & s_{6} & s_{4} \\
s_{7} & s_{6} & s_{8} & s_{5} \\
s_{4} & s_{4} & s_{5} & s_{8}
\end{array}\right), \widetilde{L}_{2}=\left(\begin{array}{lllll}
s_{8} & s_{3} & s_{5} & s_{3} \\
s_{3} & s_{8} & s_{4} & s_{6} \\
s_{5} & s_{4} & s_{8} & s_{3} \\
s_{3} & s_{6} & s_{3} & s_{8}
\end{array}\right), \\
& \widetilde{L}_{3}=\left(\begin{array}{lllll}
s_{8} & s_{6} & s_{5} & s_{4} \\
s_{6} & s_{8} & s_{6} & s_{3} \\
s_{5} & s_{6} & s_{8} & s_{2} \\
s_{4} & s_{3} & s_{2} & s_{8}
\end{array}\right), \widetilde{L}_{4}=\left(\begin{array}{llll}
s_{8} & s_{5} & s_{6} & s_{5} \\
s_{5} & s_{8} & s_{6} & s_{1} \\
s_{6} & s_{6} & s_{8} & s_{7} \\
s_{5} & s_{1} & s_{7} & s_{8}
\end{array}\right) .
\end{aligned}
$$

Compute the $\operatorname{SCDL}\left(e_{k}\right)(k=1,2,3,4)$ by Equation (2). And then, the $\operatorname{SCD}\left(e_{k}\right)(k=1,2,3,4)$ can be obtained by Equation (3). The detailed results are shown in Table 3.

Table 3. The detailed results of the $\operatorname{SCDL}\left(e_{k}\right)$ and $\operatorname{SCD}\left(e_{k}\right)$ of $e_{k}(k=1,2,3,4)$.

\begin{tabular}{cccccc}
\hline \hline SCDL and $S C D$ & Experts & $\boldsymbol{e}_{1}$ & $\boldsymbol{e}_{2}$ & $\boldsymbol{e}_{3}$ & $\boldsymbol{e}_{4}$ \\
\cline { 1 - 5 }$S C D L\left(e_{k}\right)$ & & 0.354 & 0.5 & 0.458 & 0.375 \\
$S C D\left(e_{k}\right)$ & 0.646 & 0.5 & 0.542 & 0.625 \\
\hline
\end{tabular}

Then, the objective weights of experts $e_{k}(k=1,2,3,4)$ by Equation (4) are:

$$
w_{1}^{o b j}=0.279, w_{2}^{o b j}=0.216, w_{3}^{o b j}=0.234, w_{4}^{o b j}=0.271
$$

Afterwards, we have the decision weights of experts $e_{k}(k=1,2,3,4)$ by Equation (5) ( $\left.\mu=\tau=0.5\right)$ :

$$
w_{1}=0.265, w_{2}=0.233, w_{3}=0.242, w_{4}=0.26 .
$$

Step 3. Compute the collective evaluation $P_{c}=\left(p_{i j, c}, l_{i j, c}\right)_{n \times n}$ by Equation (6):

$$
P_{c}=\left(\begin{array}{cccc}
\left(0.5, s_{8}\right) & \left(0.33, s_{3}\right) & \left(0.49, s_{5}\right) & \left(0.43, s_{2}\right) \\
\left(0.67, s_{3}\right) & \left(0.5, s_{8}\right) & \left(0.56, s_{4}\right) & \left(0.55, s_{1}\right) \\
\left(0.51, s_{5}\right) & \left(0.44, s_{4}\right) & \left(0.5, s_{8}\right) & \left(0.55, s_{2}\right) \\
\left(0.57, s_{3}\right) & \left(0.45, s_{1}\right) & \left(0.45, s_{2}\right) & \left(0.5, s_{8}\right)
\end{array}\right)
$$

Step 4. By Equation (7), the self-confidence scores $\operatorname{SCS}\left(x_{i}\right)(i=1,2,3,4)$ of all the alternatives are calculated as:

$$
\begin{aligned}
& \operatorname{SCS}\left(x_{1}\right)=2.184, \operatorname{SCS}\left(x_{2}\right)=2.182, \\
& \operatorname{SCS}\left(x_{3}\right)=2.340, \operatorname{SCS}\left(x_{4}\right)=1.752 .
\end{aligned}
$$

Thus, the ranking of alternatives is $x_{3} \succ x_{1} \succ x_{2} \succ x_{4}$. Then, the optimal solution is $x_{3}$.

\section{Analyses and Discussion}

In order to further verify the validity of the proposed GDM method in this study, this section gives some comparative analyses and discussions. In Section 5.1, the analysis of the impact of experts' self-confidence on alternative ranking in GDM is provided. And then, a sensitivity analysis of the experts' weights is provided in Section 5.2.

\subsection{The Impact of Experts' Self-Confidence on Alternative Ranking in GDM}

As far as we know, the FPRs denote that experts are fully self-confident of their evaluations. The self-confidence levels related to all fuzzy preference values are the same, that is, $l_{i j}=s_{g}$ for 
$\forall i, j=1,2, \ldots, n$. Generally, the self-confidence levels are omitted for notation simplification in FPRs. Thus, the FPRs can be seen a special case of SC-FPRs. As per the case study provided in Section 4, suppose the four experts are fully self-confident of their evaluations. Then, the FPRs, denoted as $\widetilde{P}_{k}=\left(\widetilde{p}_{i j, k}\right)(k=1,2,3,4)$ are as follows:

$$
\begin{aligned}
& \widetilde{P}_{1}=\left(\begin{array}{llll}
0.5 & 0.1 & 0.6 & 0.7 \\
0.9 & 0.5 & 0.8 & 0.6 \\
0.4 & 0.2 & 0.5 & 0.6 \\
0.3 & 0.4 & 0.4 & 0.5
\end{array}\right), \widetilde{P}_{2}=\left(\begin{array}{llll}
0.5 & 0.6 & 0.8 & 0.2 \\
0.4 & 0.5 & 0.6 & 0.7 \\
0.2 & 0.4 & 0.5 & 0.4 \\
0.8 & 0.3 & 0.6 & 0.5
\end{array}\right), \\
& \widetilde{P}_{3}=\left(\begin{array}{llll}
0.5 & 0.3 & 0.4 & 0.7 \\
0.7 & 0.5 & 0.2 & 0.4 \\
0.6 & 0.8 & 0.5 & 0.9 \\
0.3 & 0.6 & 0.1 & 0.5
\end{array}\right), \widetilde{P}_{4}=\left(\begin{array}{llll}
0.5 & 0.4 & 0.2 & 0.1 \\
0.6 & 0.5 & 0.6 & 0.5 \\
0.8 & 0.4 & 0.5 & 0.3 \\
0.9 & 0.5 & 0.7 & 0.5
\end{array}\right) .
\end{aligned}
$$

Meanwhile, the decision weights of experts $e_{k}(k=1,2,3,4)$ are:

$$
w_{1}=0.25, w_{2}=0.25, w_{3}=0.25, w_{4}=0.25 .
$$

Then, the collective FPR $\widetilde{P}_{c}=\left(\widetilde{p}_{i j, c}\right)$ can be obtained by WA operator as:

$$
\widetilde{P}_{c}=\left(\begin{array}{cccc}
0.5 & 0.35 & 0.5 & 0.43 \\
0.65 & 0.5 & 0.55 & 0.55 \\
0.5 & 0.4 & 0.5 & 0.55 \\
0.57 & 0.45 & 0.45 & 0.5
\end{array}\right) .
$$

Afterwards, by Equation (7), the SCSs of each alternative can be calculated. And then, we can get the rankings of alternatives of collective evaluations. The detailed results are shown in Table 4 .

Table 4. The detailed results of the special case of the SC-FPRs $(i=1,2,3,4)$.

\begin{tabular}{cccc}
\hline \multicolumn{5}{c}{$\widetilde{\boldsymbol{P}}_{\boldsymbol{c}}$} & $\boldsymbol{S C S}\left(\boldsymbol{x}_{\boldsymbol{i}}\right)$ & Rankings of Alternatives \\
\hline$\left(\begin{array}{cccc}0.5 & 0.35 & 0.5 & 0.43 \\
0.65 & 0.5 & 0.55 & 0.55 \\
0.5 & 0.4 & 0.5 & 0.55 \\
0.57 & 0.45 & 0.45 & 0.5\end{array}\right)$ & $\operatorname{SCS}\left(x_{1}\right)=3.55$ & \\
$\operatorname{SCS}\left(x_{2}\right)=4.50$ & $\left.x_{2} \succ x_{3}\right)=4.00$ & \\
& $\operatorname{SCS}\left(x_{4}\right)=3.95$ & \\
\hline
\end{tabular}

It is clearly that the rankings of alternatives in Table 4 are different from the results which we have obtained in Section 4.2. Thus, it validates that experts' self-confidence levels have an important influence on the final decision in GDM problems.

\subsection{Sensitivity Analysis of the Decision Weight}

In this section, a sensitive analysis is conducted to investigate the influence of coefficients $\mu$ and $\tau$ on the rankings of alternatives. To save the space, the detailed processes are omitted here, and the computation results are directly shown in Table 5.

From Table 5, it can be seen that the different values of $\mu$ and $\tau$ have an influence on the ranking of the alternatives. Additionally, Figure 2 shows the several alternatives ranking with different values of $\mu$ and $\tau$, where the blue line represents the final alternative rankings. Clearly, from Figure 2 we also reach similar conclusions. 
Table 5. Rankings of the alternatives with different values of $\mu$ and $\tau$.

\begin{tabular}{cccccc}
\hline$\mu$ and $\boldsymbol{\tau}$ & $\boldsymbol{S C S}\left(\boldsymbol{x}_{1}\right)$ & $\boldsymbol{S C S}\left(\boldsymbol{x}_{2}\right)$ & $\boldsymbol{S C S}\left(\boldsymbol{x}_{3}\right)$ & $\boldsymbol{S C S}\left(\boldsymbol{x}_{4}\right)$ & Rankings of Alternatives \\
\hline$\mu=0, \tau=1$ & 2.1847 & 2.1971 & 2.3505 & 1.7678 & $x_{3} \succ x_{2} \succ x_{1} \succ x_{4}$ \\
$\mu=0.1, \tau=0.9$ & 2.1868 & 2.1949 & 2.3504 & 1.7679 & $x_{3} \succ x_{2} \succ x_{1} \succ x_{4}$ \\
$\mu=0.2, \tau=0.8$ & 2.1890 & 2.1927 & 2.3504 & 1.7680 & $x_{3} \succ x_{2} \succ x_{1} \succ x_{4}$ \\
$\mu=0.3, \tau=0.7$ & 2.1912 & 2.1905 & 2.3503 & 1.7681 & $x_{3} \succ x_{1} \succ x_{2} \succ x_{4}$ \\
$\mu=0.4, \tau=0.6$ & 2.1933 & 2.1882 & 2.3503 & 1.7682 & $x_{3} \succ x_{1} \succ x_{2} \succ x_{4}$ \\
$\mu=0.5, \tau=0.5$ & 2.1838 & 2.1820 & 2.3399 & 1.7518 & $x_{3} \succ x_{1} \succ x_{2} \succ x_{4}$ \\
$\mu=0.6, \tau=0.4$ & 2.1976 & 2.1838 & 2.3502 & 1.7684 & $x_{3} \succ x_{1} \succ x_{2} \succ x_{4}$ \\
$\mu=0.7, \tau=0.3$ & 2.1998 & 2.1816 & 2.3501 & 1.7685 & $x_{3} \succ x_{1} \succ x_{2} \succ x_{4}$ \\
$\mu=0.8, \tau=0.2$ & 2.2019 & 2.1794 & 2.3501 & 1.7686 & $x_{3} \succ x_{1} \succ x_{2} \succ x_{4}$ \\
$\mu=0.9, \tau=0.1$ & 2.2041 & 2.1772 & 2.3500 & 1.7687 & $x_{3} \succ x_{1} \succ x_{2} \succ x_{4}$ \\
$\mu=1, \tau=0$ & 2.2063 & 2.1750 & 2.3500 & 1.7688 & $x_{3} \succ x_{1} \succ x_{2} \succ x_{4}$ \\
\hline
\end{tabular}

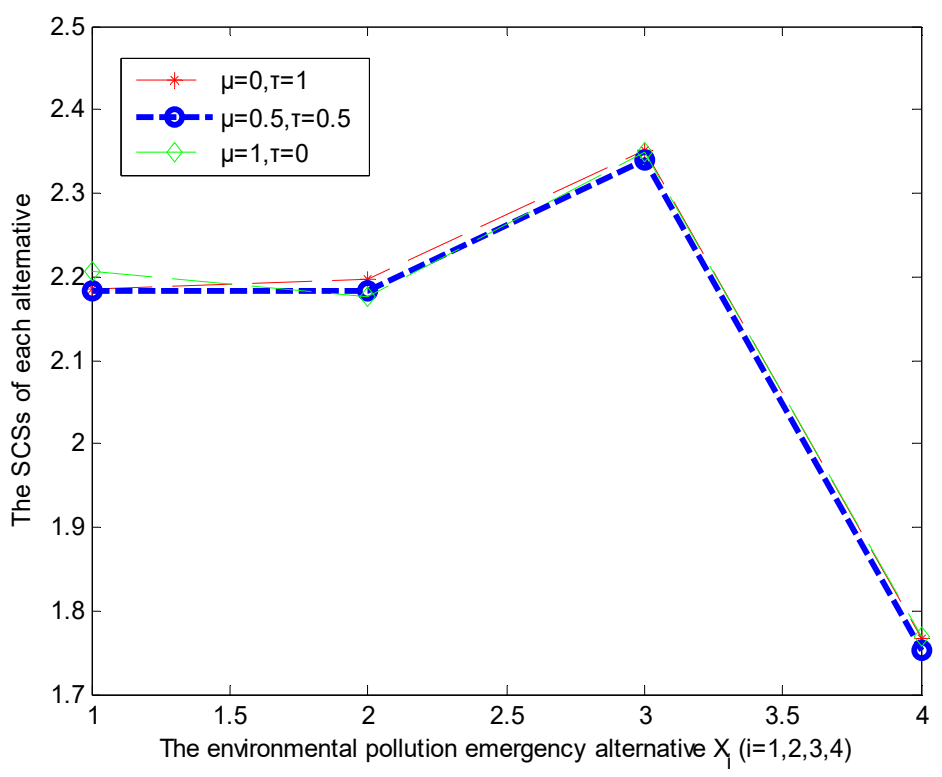

Figure 2. The alternatives ranking with different values of $\mu$ and $\tau$.

\section{Conclusions}

To improve the quality of emergency management decisions, this paper focuses on the GDM considering self-confidence behaviors and its application in environmental pollution emergency management. The major contributions are summarized below:

(1) Experts are allowed to use SC-FPRs to express their assessment information, so as to deal with the self-confidence psychological behavior well in environmental pollution emergency management. Meanwhile, some new operational laws of 2-tuples in SC-FPR are presented to apply to GDM problems.

(2) A novel determination of the experts' weights is developed in environmental pollution emergency management. That is, we integrate the subjective weights assigned by the organizer, and the objective weights determined by the experts' SCDs to determine the importance degree of experts in environmental pollution emergency management. An SCD is proposed to measure the overall self-confidence levels of experts on their evaluations. Subsequently, the objective weights of experts in environmental pollution emergency management can be assigned by the values of the SCDs of experts.

(3) An SCS function is designed to obtain the alternatives rankings in environmental pollution emergency management. We compute the values of the SCSs for all the alternatives, and then rank them. The best alternative is obtained according to the largest value of SCS. 
As we all know, the moderate self-confidence of experts is conductive to decision making while overconfident behaviors have a negative impact on the efficiency and quality of final decision(s) [36,37]. Thus, the overconfidence behaviors detection and management of experts in real GDM problems is still an interesting topic for the future. In addition, with the rapid development of science and technology, such as e-democracy [38], social networks [39,40], and public participation [41], more and more decision makers are involved in decision making. This suggests large scale group decision making (LSGDM) will become a research hotspot [42-48]. Meanwhile, the consensus reaching process (CRP) is an important topic in decision analysis [49,50]. Hence, whether the proposed GDM approach can be utilized to discuss the CRP for LSGDM problems is worthy of discussion.

Author Contributions: The research was designed and performed by X.L. and Y.G. The data was collected and analyzed by X.L. and W.Z. The paper was written by X.L., and finally checked and revised by Y.X., Y.G., W.Z. and F.H. All authors read and approved the final manuscript.

Acknowledgments: The work was supported by National Key R\&D Program of China (Grant No. 2017YFC0404600), National Natural Science Foundation of China (NSFC) under Grants (71871085, 71471056), Qing Lan Project of Jiangsu Province. Additionally, Xia Liu and Weike Zhang gratefully acknowledge the financial support of the China Scholarship Council (Nos. 201706710084, 201806240231).

Conflicts of Interest: The authors declare no conflict of interest.

\section{Appendix A}

Table A1. Symbol descriptions.

\begin{tabular}{ll}
\hline \multicolumn{1}{c}{ Notations } & \multicolumn{1}{c}{ Descriptions } \\
\hline$X=\left\{x_{1}, x_{2}, \ldots, x_{n}\right\}$ & Finite set of environmental pollution emergency alternatives \\
$E=\left\{e_{1}, e_{2}, \ldots, e_{m}\right\}$ & Set of experts (decision makers) \\
$S^{S L}=\left\{s_{i} \mid i=0, \ldots, g\right\}$ & Set of the linguistic self-confidence of expert \\
$P_{k}=\left(p_{i j, k}, l_{i j, k}\right)_{n \times n}$ & The SC-FPR of expert $e_{k}$ \\
$\widetilde{L}=\left(\widetilde{l}_{i j}\right)_{n \times n}$ & The self-confidence matrix of expert $e_{k}$ \\
$S C D L\left(e_{k}\right)$ & Self-confidence deviation level of $e_{k}$ \\
$S C D\left(e_{k}\right)$ & Self-confidence degree level of $e_{k}$ \\
$w^{\text {sub }}=\left(w_{1}^{s u b}, w_{2}^{\text {sub }}, \ldots, w_{m}^{\text {sub }}\right)$ & Subjective weight set of expert \\
$w^{o b j}=\left(w_{1}^{o b j}, w_{2}^{o b j} \ldots w_{m}^{o b j}\right)$ & Objective weight set of expert \\
$w=\left(w_{1}, w_{2}, \ldots, w_{k}\right)$ & Decision weight set of expert \\
$\mu$ and $\tau$ & The parameters to control the weight between subjective and objective weights of expert \\
$P_{c}=\left(p_{i j, c}, l_{i j, c}\right)_{n \times n}$ & The SC-FPR of collective \\
$S C S\left(x_{i}\right)$ & The self-confidence score function of $x_{i}$ \\
\hline
\end{tabular}

\section{References}

1. Hochbaum, D.S.; Levin, A. Methodologies and algorithms for group-rankings decision. Manag. Sci. 2006, 52, 1394-1408. [CrossRef]

2. Herrera, F.; Herrera-Viedma, E.; Chiclana, F. Multiperson decision-making based on multiplicative preference relations. Eur. J. Oper. Res. 2001, 129, 372-385. [CrossRef]

3. Xu, Y.J.; Liu, X.; Wang, H.M. The additive consistency measure of fuzzy reciprocal preference relations. Int. J. Mach. Learn. Cybern. 2018, 9, 1141-1152. [CrossRef]

4. Millet, I. The effectiveness of alternative preference elicitation methods in the analytic hierarchy process. J. Multi-Criteria Decis. Anal. 1997, 6, 41-51. [CrossRef]

5. Orlovsky, S. Decision-making with a fuzzy preference relation. Fuzzy Sets Syst. 1978, 1, 155-167. [CrossRef]

6. Chiclana, F.; Herrera, F.; Herrera-Viedma, E. Integrating multiplicative preference relations in a multipurpose decision-making model based on fuzzy preference relations. Fuzzy Sets Syst. 2001, 122, 277-291. [CrossRef]

7. Xu, Y.J.; Cabrerizo, F.J.; Herrera-Viedma, E. A consensus model for hesitant fuzzy preference relations and its application in water allocation management. Appl. Soft Comput. 2017, 58, 265-284. [CrossRef]

8. Liao, H.C.; Si, G.S.; Xu, Z.S.; Fujita, H. Hesitant fuzzy linguistic preference utility set and its application in selection of fire rescue plans. Int. J. Environ. Res. Public Health 2018, 15, 664. [CrossRef] 
9. Tang, M.; Liao, H.C.; Li, Z.M.; Xu, Z.S. Nature disaster risk evaluation with a group decision making method based on incomplete hesitant fuzzy linguistic preference relations. Int. J. Environ. Res. Public Health 2018, 15, 751. [CrossRef]

10. Zhang, Z.; Kou, X.Y.; Yu, W.Y.; Guo, C.H. On priority weights and consistency for incomplete hesitant fuzzy preference relations. Knowl.-Based Syst. 2018, 143, 115-126. [CrossRef]

11. Zhang, Z.; Guo, C.H. Deriving priority weights from intuitionistic multiplicative preference relations under group decision-making settings. J. Oper. Res. Soc. 2017, 68, 1582-1599. [CrossRef]

12. Dong, Y.C.; Liu, Y.T.; Liang, H.M.; Chiclana, F.; Herrera-Viedma, E. Strategic weight manipulation in multiple attribute decision making. Omega 2018, 75, 154-164. [CrossRef]

13. Bénabou, R.; Tirole, J. Self-confidence and personal motivation. Q. J. Econ. 2002, 117, 871-915. [CrossRef]

14. Hinsz, V.B. Cognitive and consensus processes in group recognition memory performance. J. Personal. Soc. Psychol. 1990, 59, 705. [CrossRef]

15. Stephenson, G.M.; Abrams, D.; Wagner, W.; Wade, G. Partners in recall: Collaborative order in the recall of a police interrogation. Br. J. Soc. Psychol. 1986, 25, 341-343. [CrossRef]

16. Johnson, H.H.; Torcivia, J.M. Group and individual performance on a single-stage task as a function of distribution of individual performance. J. Exp. Soc. Psychol. 1967, 3, 266-273. [CrossRef]

17. Ureña, R.; Chiclana, F.; Fujita, H.; Herrera-Viedma, E. Confidence-consistency driven group decision making approach with incomplete reciprocal intuitionistic preference relations. Knowl.-Based Syst. 2015, 89, 86-96. [CrossRef]

18. Liu, W.Q.; Dong, Y.C.; Chiclana, F.; Cabrerizo, F.J.; Herrera-Viedma, E. Group decision-making based on heterogeneous preference relations with self-confidence. Fuzzy Optim. Decis. Mak. 2017, 16, 429-447. [CrossRef]

19. Su, L.Y.; Liu, J.L.; Christensen, P. Comparative study of water resource management policies between China and Denmark. Procedia Environ. Sci. 2010, 2, 1775-1798. [CrossRef]

20. Zhang, X.-J.; Chen, C.; Ding, J.-Q.; Hou, A.; Li, Y.; Niu, Z.-B.; Su, X.-Y.; Xu, Y.-J.; Laws, E.A. The 2007 water crisis in Wuxi, China: Analysis of the origin. J. Hazard. Mater. 2010, 182, 130-135. [CrossRef]

21. Zhong, L.; Zhang, Y.; Yang, D.D.; Lu, Z.L. Introduction and reflection of cadmium pollution accident occurred in LongJiang River of Guangxi Province. Chin. J. Chem. Educ. 2013, 6, 1.

22. Miao, X.; Tang, Y.H.; Wong, C.W.; Zang, H.Y. The latent causal chain of industrial water pollution in China. Environ. Pollut. 2015, 196, 473-477. [CrossRef] [PubMed]

23. Yuan, Q.; Gascó, M. Citizens' use of microblogging and government communication during emergencies: A case study on water contamination in Shanghai. First Monday 2018, 23. [CrossRef]

24. Yang, J.M. Environmental emergency response plan. In Environmental Management in Mega Construction Projects; Springer: Berlin, Germany, 2017; pp. 275-283.

25. Shao, C.F.; Yang, J.; Tian, X.G.; Ju, M.T.; Huang, L. Integrated environmental risk assessment and whole-process management system in chemical industry parks. Int. J. Environ. Res. Public Health 2013, 10, 1609-1630. [CrossRef] [PubMed]

26. Zhang, Q.; Wang, M. Strengthen The quality management of sudden environmental pollution emergency monitoring. J. Environ. Manag. Coll. China 2006, 2, 30.

27. Marchese, D.; Reynolds, E.; Bates, M.E.; Morgan, H.; Clark, S.S.; Linkov, I. Resilience and sustainability: Similarities and differences in environmental management applications. Sci. Total Environ. 2018, 613, 1275-1283. [CrossRef] [PubMed]

28. Cao, G.; Yang, L.; Liu, L.; Ma, Z.; Wang, J.; Bi, J. Environmental incidents in China: Lessons from 2006 to 2015. Sci. Total Environ. 2018, 633, 1165-1172. [CrossRef]

29. Ayeni, A.O. Environmental policies for emergency management and public safety: Implementing green policy and community participation. In Emergency and Disaster Management: Concepts, Methodologies, Tools, and Applications; IGI Global: Hershey, PA, USA, 2019; pp. 903-922.

30. Rämö, R.A.; van den Brink, P.J.; Ruepert, C.; Castillo, L.E.; Gunnarsson, J.S. Environmental risk assessment of pesticides in the River Madre de Dios, Costa Rica using PERPEST, SSD, and msPAF models. Environ. Sci. Pollut. Res. 2018, 25, 13254-13269. [CrossRef]

31. Herrera, F.; Martínez, L. A 2-tuple fuzzy linguistic representation model for computing with words. IEEE Trans. Fuzzy Syst. 2000, 8, 746-752. 
32. Dong, Y.C.; Herrera-Viedma, E. Consistency-driven automatic methodology to set interval numerical scales of 2-tuple linguistic term sets and its use in the linguistic GDM with preference relation. IEEE Trans. Cybern. 2015, 45, 780-792. [CrossRef]

33. Martínez, L.; Herrera, F. An overview on the 2-tuple linguistic model for computing with words in decision making: Extensions, applications and challenges. Inf. Sci. 2012, 207, 1-18. [CrossRef]

34. Zadeh, L.A. A note on Z-numbers. Inf. Sci. 2011, 181, 2923-2932. [CrossRef]

35. Liu, X.; Xu, Y.J.; Montes, R.; Dong, Y.C.; Herrera, F. Analysis of self-confidence indices-based additive consistency for fuzzy preference relations with self-confidence and its application in group decision making. Int. J. Intell. Syst. 2018. [CrossRef]

36. Zacharakis, A.L.; Shepherd, D.A. The nature of information and overconfidence on venture capitalists' decision making. J. Bus. Ventur. 2001, 16, 311-332. [CrossRef]

37. Moore, D.A.; Healy, P.J. The trouble with overconfidence. Psychol. Rev. 2008, 115, 502. [CrossRef]

38. Gayo-Avello, D. Social media, democracy, and democratization. IEEE Multimed. 2015, 22, 10-16. [CrossRef]

39. De Meo, P.; Ferrara, E.; Rosaci, D.; Sarné, G.M. Trust and compactness in social network groups. IEEE Trans. Cybern. 2015, 45, 205-216. [CrossRef] [PubMed]

40. Wu, J.; Xiong, R.Y.; Chiclana, F. Uninorm trust propagation and aggregation methods for group decision making in social network with four tuple information. Knowl.-Based Syst. 2016, 96, 29-39. [CrossRef]

41. De Santo, E.M. Assessing public "participation" in environmental decision-making: Lessons learned from the UK Marine Conservation Zone (MCZ) site selection process. Mar. Policy 2016, 64, 91-101. [CrossRef]

42. Liu, X.; Xu, Y.J.; Montes, R.; Ding, R.X.; Herrera, F. Alternative ranking-based clustering and reliability index-based consensus reaching process for hesitant fuzzy large scale group decision making. IEEE Trans. Fuzzy Syst. 2019, 27, 159-171. [CrossRef]

43. Zhang, H.J.; Dong, Y.C.; Herrera-Viedma, E. Consensus building for the heterogeneous large-scale GDM with the individual concerns and satisfactions. IEEE Trans. Fuzzy Syst. 2018, 26, 884-898. [CrossRef]

44. Xu, Y.J.; Wen, X.W.; Zhang, W.C. A two-stage consensus method for large-scale multi-attribute group decision making with an application to earthquake shelter selection. Comput. Ind. Eng. 2018, 116, 113-129. [CrossRef]

45. Li, C.-C.; Dong, Y.C.; Herrera, F. A consensus model for large-scale linguistic group decision making with a feedback recommendation based on clustered personalized individual semantics and opposing consensus groups. IEEE Trans. Fuzzy Syst. 2018. [CrossRef]

46. Palomares, I.; Martínez, L.; Herrera, F. A consensus model to detect and manage noncooperative behaviors in large-scale group decision making. IEEE Trans. Fuzzy Syst. 2014, 22, 516-530. [CrossRef]

47. Wu, Z.B.; Xu, J.P. A consensus model for large-scale group decision making with hesitant fuzzy information and changeable clusters. Inf. Fusion 2018, 41, 217-231. [CrossRef]

48. Zhang, Z.; Guo, C.H.; Martínez, L. Managing multigranular linguistic distribution assessments in large-scale multiattribute group decision making. IEEE Trans. Syst. Man Cybern. Syst. 2017, 47, 3063-3076. [CrossRef]

49. Zhang, Z.; Guo, C.H. Consistency and consensus models for group decision-making with uncertain 2-tuple linguistic preference relations. Int. J. Syst. Sci. 2016, 47, 2572-2587. [CrossRef]

50. Zhang, B.W.; Dong, Y.C.; Herrera-Viedma, E. Group decision making with heterogeneous preference structures: An automatic mechanism to support consensus reaching. Group Decis. Negot. 2019. [CrossRef]

(C) 2019 by the authors. Licensee MDPI, Basel, Switzerland. This article is an open access article distributed under the terms and conditions of the Creative Commons Attribution (CC BY) license (http://creativecommons.org/licenses/by/4.0/). 